\title{
Industrial Process Management Using LabVIEW
}

\author{
S.Venkatlakshmi ${ }^{1}$, S.Vivekanandhan ${ }^{2}$, S.Revathi ${ }^{3}$, E.M.Shakthi Arul ${ }^{4}$, \\ C.Paramasivam ${ }^{5}$ (Assistant Professor) \\ Department of ECE, K.S.Rangasamy College of Technology, Tiruchengode
}

\begin{abstract}
Nowadays process management is a tedious task in the industry. We plan to propose a LabVIEW based intelligent multi parameter monitoring system designed using RS232 and Microcontroller aids in the measurement and control of various Global Parameters. For data collection in the industry is a difficult task in real time execution of events with industrial process control and automation. We proposed two slaves for measuring various industrial parameters to monitor and control industrial process. Data acquired from each slave is processed and sent to Master that compile data received from different slaves and send this information to the system configured with LabVIEW platform. This enables us to view and track the online changes encountered in the particular parameter of all the parameters. One of the main advantages of this proposal is, it allows us to view all the parameter readings simultaneously on the front panel in LabVIEW. The Graph drawn on the front panel keeps on tracking the changes on the parameter. The parameters supported by this project includes: current, voltage, temperature, frequency, light intensity, logic switches, water level identifier, and alarm. This Project can be implemented in any of the process industries where there is a need for Simultaneous and fast acquiring of data and control.
\end{abstract}

Keywords: LabVIEW, RS232, Micro-controller, data acquisition

\section{INTRODUCTION}

At present DAQ systems are widely popular in industry in the control and remote monitoring of system status and physiological parameters.The paper designed the virtual test platform for communication with measurement and control. After testing, the platform has high speed of data acquisition, is able to effectively deal with parameters of the object for testing and output the result, as well as can well communicate with other devices. The interaction with physical quantities to be measured is performing with specific hardware or PC standard interfaces [1].

Multiple embedded nodes are measuring various industrial parameters to monitor and control industrial process. Acquired data display at each node and sent to master processor that compile the acquired information and send to remote location [2].

G language LabVIEW can be effectively achieved a virtual panel in the personal computer. Virtual instrument panel has the virtual switches, buttons and knobs with the same function of real instrument. User operates the instrument through the friendly graphical interface, thus completing the measurement signal acquisition, analysis, judgment, display, and data access. The paper adds the value towards the low cost, less manufacturing time, ease of implementation with reliable measuring, controlling and data logging demands of industry [4].

\section{SYSTEM DESIGN}

\subsection{DESIGN OF REAL TIME DATA ACQUISITION SYSTEM}

Design of data acquisition system is demonstrated for measurement of parameters like temperature, light, voltage, current etc. by acquiring data using different sensors at different locations and communicating with the user using Ethernet module. System description divided into two parts, consisting of hardware and Software description. 


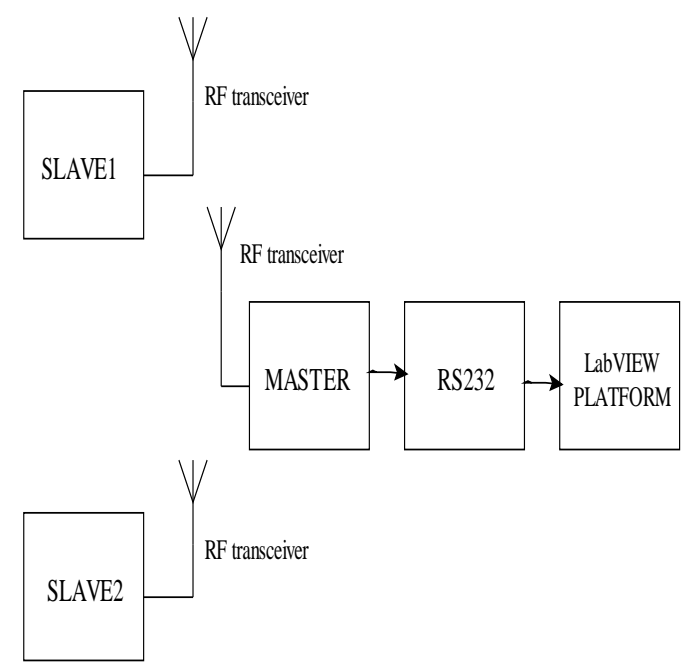

Figure1. Block diagram of Industrial process management

\section{Hardware Description}

In the design of real time data acquisition system, we used several sensors like LDR, temperature sensors that will observe the different parameters. The ADC for receiving the analog input and converts it into digital data that will be process by Slave controller. We have used PIC18F4550 as master controller. We are using master and slave method for realization of this DAQ system.

For slaves we have used 16 bit microcontroller name PIC18F4550. The slave takes the decision as per instruction stored in its program memory. The signal can be sent at faraway places by using Ethernet module and display waveforms of acquired signals on front panel designed with LabVIEW.

\subsection{MICROCONTROLLER}

Microcontrollers are small and cost effective but self-contained computer chips used for embedded applications in industrial and consumer electronics products. In this system, we are using PIC18F4550 microcontroller as slaves and also PIC18F4550 as master controller. The PIC18F4550 performs the major role in this project because we can connect this through the USB channel. The pin diagram was shown in Fig no 2.

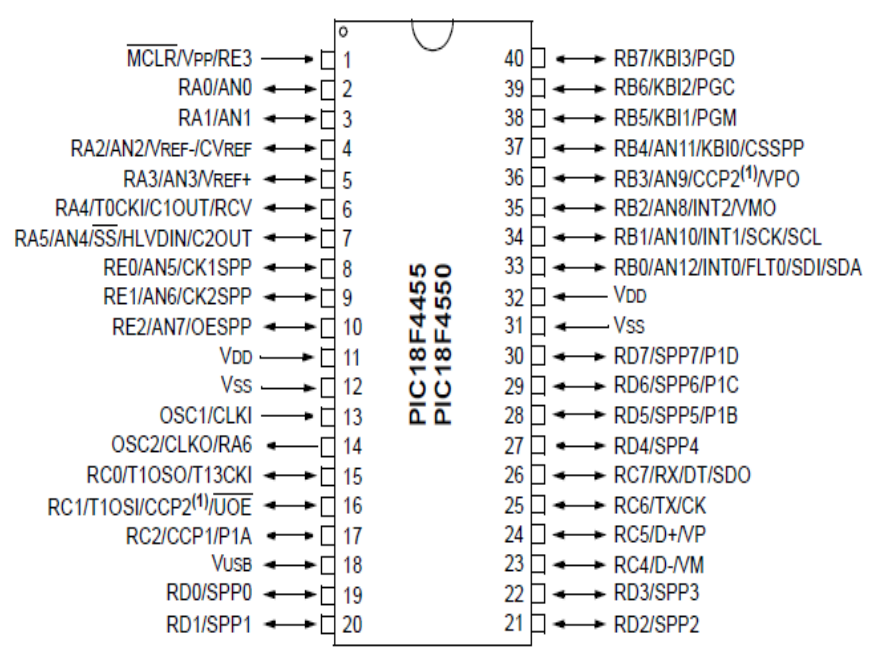

Figure2. Pin diagram of PIC18F4550

\subsection{TEMPERATURE MEASUREMENT}

The LM35 series are precision integrated-circuit temperature sensors, whose output voltage linearly calibrated directly in ${ }^{\circ}$ Celsius (Centigrade) i.e. Linear $+10.0 \mathrm{mV} /{ }^{\circ} \mathrm{C}$ scale factor with $0.5^{\circ} \mathrm{C}$ accuracy guarantee able $\left(\right.$ at $\left.+25^{\circ} \mathrm{C}\right)$ and rated for full $-55^{\circ}$ to $+150^{\circ} \mathrm{C}$ range [1]. It operates from 4 to 30 volts and draws less than 60 $\mu \mathrm{A}$. Schematic diagram of LM35 was shown in Figure 3. 


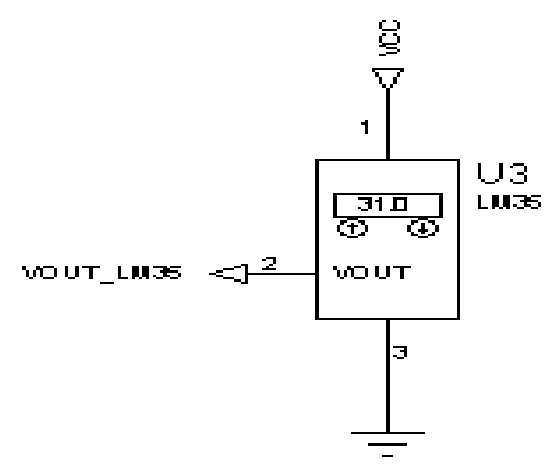

Figure 3.Schematic for LM35 IC temperature measurement

\subsection{WATER LEVEL IDENTIFIER}

The circuit indicates the amount of water in the tank head, but also gives an alarm when the tank is full [1].This circuit uses the widely available to show IC number CD4066 bilateral switch CMOS IC to the water level through LEDs.

If the water is empty the wires in the tank are open circuit and the $180 \mathrm{~K}$ resistors pulls the switch to open the little switches and LEDs are off. When the water begins to fill the first connected to the reservoir in the S1 and the + supply are shorted by water. This closes the S1 and turns the LED1 ON. As the water further into the tank, LEDS2, 3 to 4 pm light gradually filled.

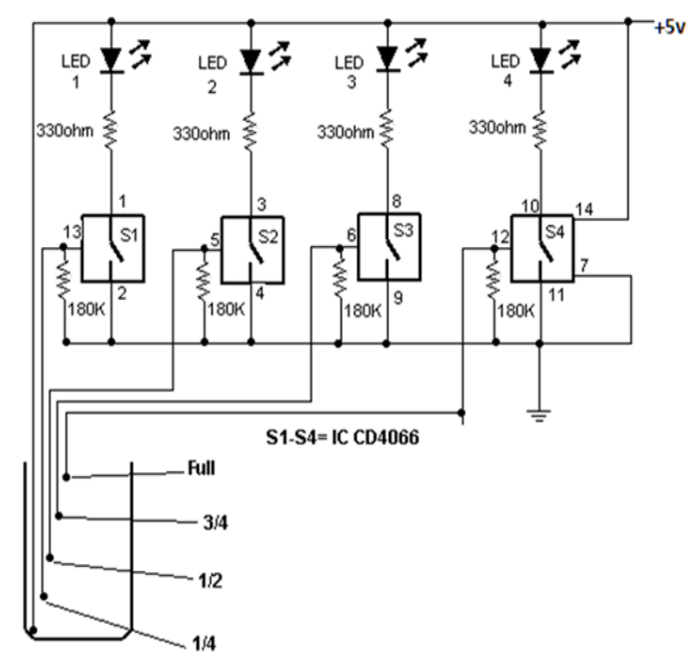

Figure4. Water level sensor circuit

\subsection{LIGHT INTENSITY MEASUREMENT}

A Light / Dark activated switch is a circuit which was shown Fig no.3.8 that will measure the light level and will turn on or off a relay accordingly. We use an LDR (Light Depended Resistor) to measure the light level. 


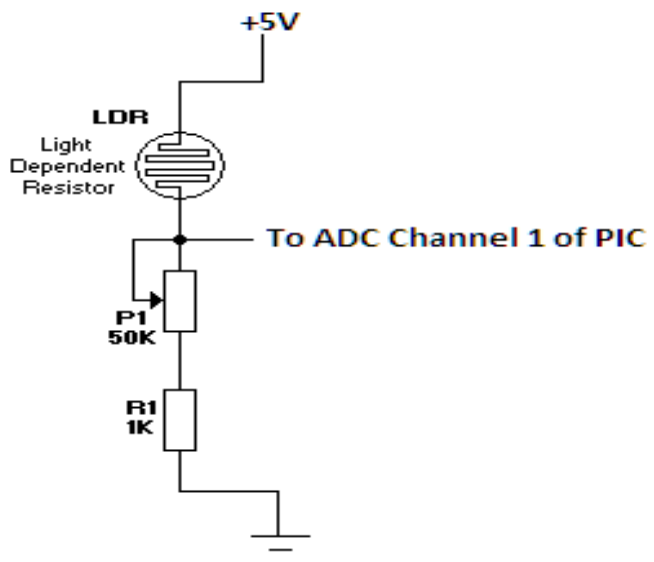

Figure5. Light/Dark activated relay circuit

The circuit is a simple transistor switch with the base of the transistor connected to a voltage divider [2]. The voltage divider has two resistors. The first is the $100 \mathrm{~K}$ potentiometer plus the protective $1 \mathrm{~K}$ resistor. The second resistor is the LDR. As light falls on the surface of the LDR, the LDR changes it's resistance. The more the light, the less the resistance of the LDR, the less the resistance, the less the voltage drop across it. The less the light, the more the resistance and thus the more the voltage drop across it. As the voltage drop increases, so does the VB of the $2 \mathrm{~N} 2222$ transistor and therefore the ICE increases accordingly, until the time that the current is enough to actuate the relay.

The amount of light needed to actuate the relay can be changed by changing the $100 \mathrm{~K}$ potentiometer. Basically, any change to the potentiometer will have an effect to the voltage drop of the LDR, as they are both members of the voltage divider described above. The $1 \mathrm{~N} 4001$ diode is used to eliminate any back voltage when the relay is disarmed. It is very important to have this diode because without it, the transistor may be damaged. The circuit Figure no.3.8 b) dark activated relay senses darkness. As the light level decreases and LDR meets the maximum threshold resistance, the circuit automatically switches on the LED D1. A dark detector can be made using a variable resistor. The sensitivity of the circuit can be adjusted with a variable resistor.

High resistance $\rightarrow$ more darkness to switch on the LED Low resistance $\rightarrow$ less darkness to switch on the LED

As the light level increases and LDR meets the lowest threshold resistance, the circuit automatically turns on the LED D1. We can adjust the sensitivity using the preset VR1-10K.

\section{Less resistance (vr1) $\rightarrow$ \\ Less darkness to switch off the LED \\ High resistance (vr1) $\rightarrow$ \\ More darkness to switch off the LED}

\subsection{ALARM}

The design of alarm system used in Industrial process management is similar to the design used for fire alarm system in smart house [2]. It is divided into three parts; the first part is the signal that reaches from alarm sensors when its trigger threshold has been reached after any a specific danger in the industry. The second part is the output signal that sends after the processing of input signal, and final part is the controlling system and data processing by LabVIEW.

\subsection{LOGIC SWITCHES}

A microcontroller can't make any decisions on controlling something in the outside world without sensing something about it. The simplest thing for a microcontroller to check is the status of a switch. Switches can be used as operator controls. They can sense if a door is open or closed. A limit switch can detect if a part of a machine has reached a certain position. Switches can be used for many purposes, but they can be in only one of two states: On (closed) or off (open). 


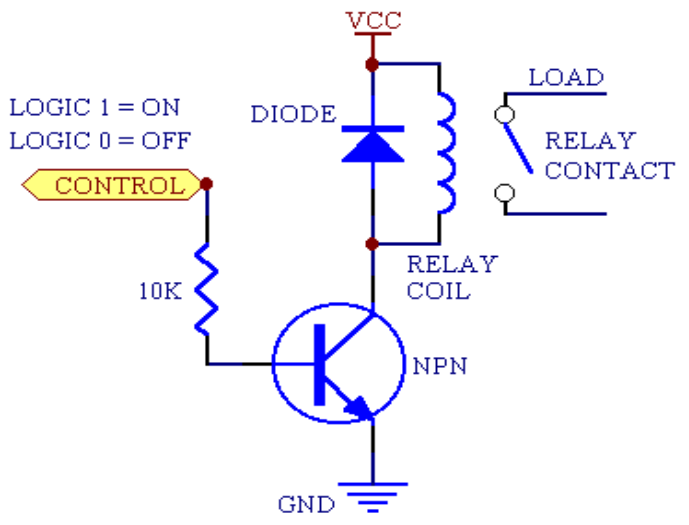

Figure7. Interfacing circuit of Microcontroller to logic Switches

Figure no 7 shows two common ways to interface switches to a microcontroller input. Input P0 uses R1 as a pull up. If SW1 is open, P0 will be high, and read as a logical 1. When SW1 is closed, pin P0 is shorted to ground, or $0 \mathrm{~V}$, and $\mathrm{P} 0$ will read as a logical 0 .

\subsection{VOLTAGE MEASUREMENT}

Voltage is the difference of electrical potential between two points of an electrical or electronic circuit, expressed in volts. It measures the potential energy of an electric field to cause an electric current in an electrical conductor. Most measurement devices can measure voltage. Two common voltage measurements are direct current (DC) and alternating current (AC). Although voltage measurements are the simplest of the different types of analog measurements, they present unique challenges due to noise considerations.

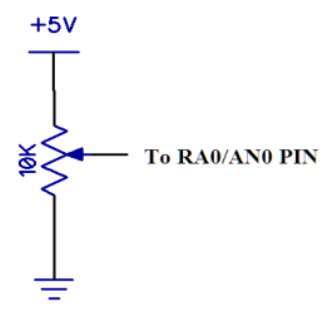

Figure 8.Voltage measurement circuit

\subsection{CURRENT MEASUREMENT}

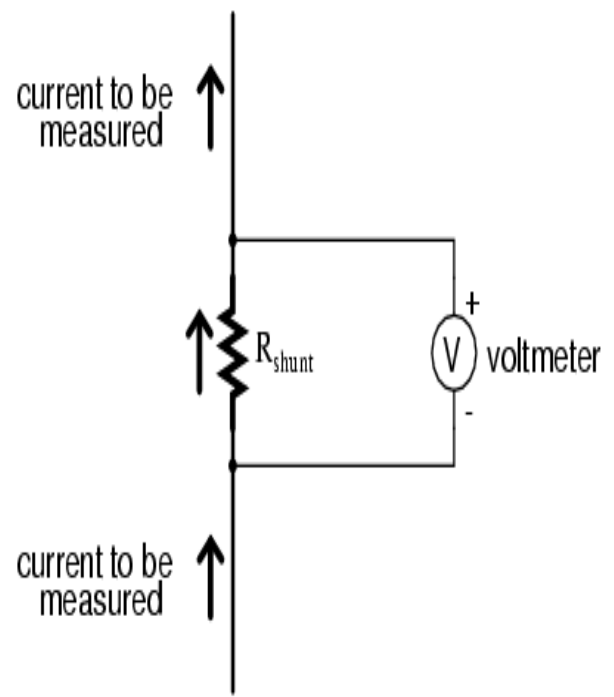

Figure9. Ammeter circuit 
In ammeter designs, external resistors added to extend the usable range of the movement are connected in parallel with the movement rather than in series as is the case for voltmeters. This is because we want to divide the measured current, not the measured voltage, going to the movement, and because current divider circuits are always formed by parallel resistances. Taking the same meter movement in Fig no9 as the voltmeter example, we can see that it would make a very limited instrument by itself, full-scale deflection occurring at only $1 \mu \mathrm{A}$.

\subsection{FREQUENCY MEASUREMENT}

In order to understand the effect of frequency on the various parameters; let us consider the following example. Consider a coil of negligible resistance and inductance $60 \mathrm{mH}$, connected to $230 \mathrm{~V}, 50 \mathrm{HZ} 1$ phase supply.

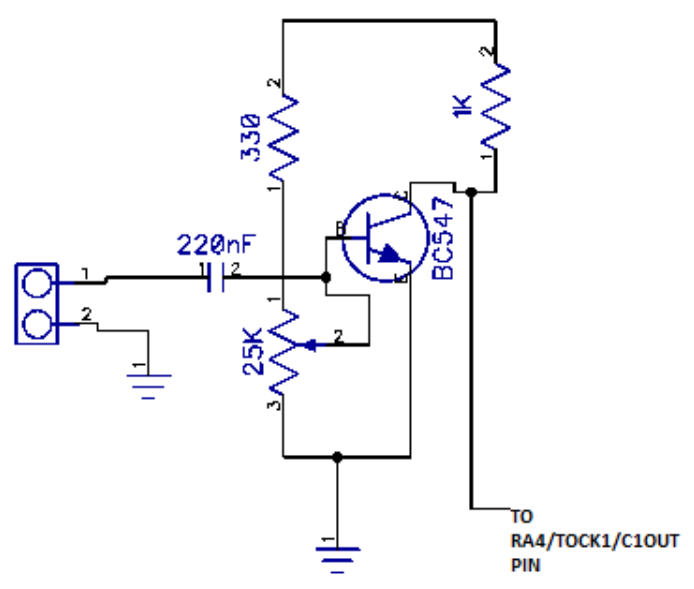

Figure 10.Frequency measurement circuit

\section{SOFTWARE DESCRIPTION Labview}

LabVIEW front panel is designed for user interface to display waveforms of measured physical quantities, control number of byte counts, setting baud rate, selection of communication port number i.e. VISA resources name, error control techniques etc. S Graphical programming is used in LabVIEW and front panel along with its block diagram.

The virtual instrument designed in LabVIEW environment is able to receive binary equivalent of physical quantity from serial port connected to embedded board and display waveform on waveform chart, it also record the received values in a standard spreadsheet, then a application program running in PC.

\subsection{LABVIEW SOFTWARE INTERFACE}

Universal asynchronous receiver transmitter used here to interface computer through 9-pin RS232 port to display acquired signal waveform with front panel of LabVIEW platform. The LabVIEW front panel designed for user interface to display waveforms of measured physical quantities, control number of byte counts, setting baud rate, selection of communication port number i.e. VISA resources name, error control techniques etc.

Initializes the serial port specified by VISA resource name to the specified settings. Wire data to the VISA resource name input to determine the polymorphic instance to use or manually select the instance. VISA configure port representation diagram was shown in Figure 11. 


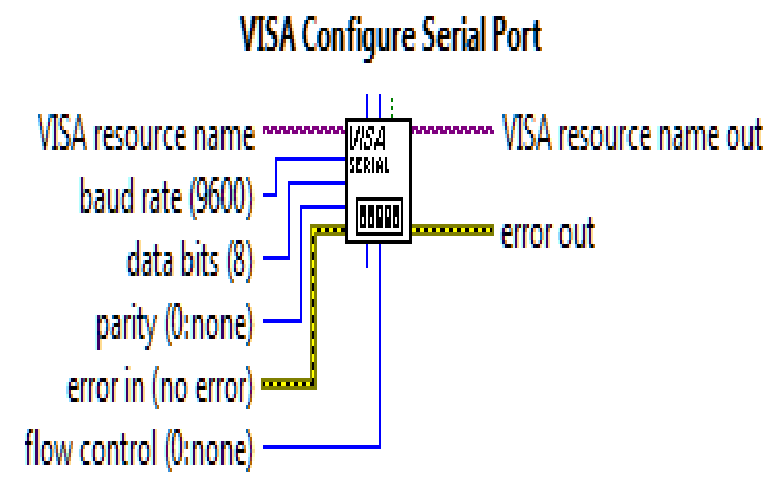

Figure 11.VISA configure serial port

\subsection{BLOCK DIAGRAM}

The programming in LabVIEW is graphical programming and performs in block diagram as shown in Figure 11 The system has been implemented, tested successfully and achieved reliable transmission of data to the remote site and representation of waveform along with logging of data in excel sheet using LabVIEW.

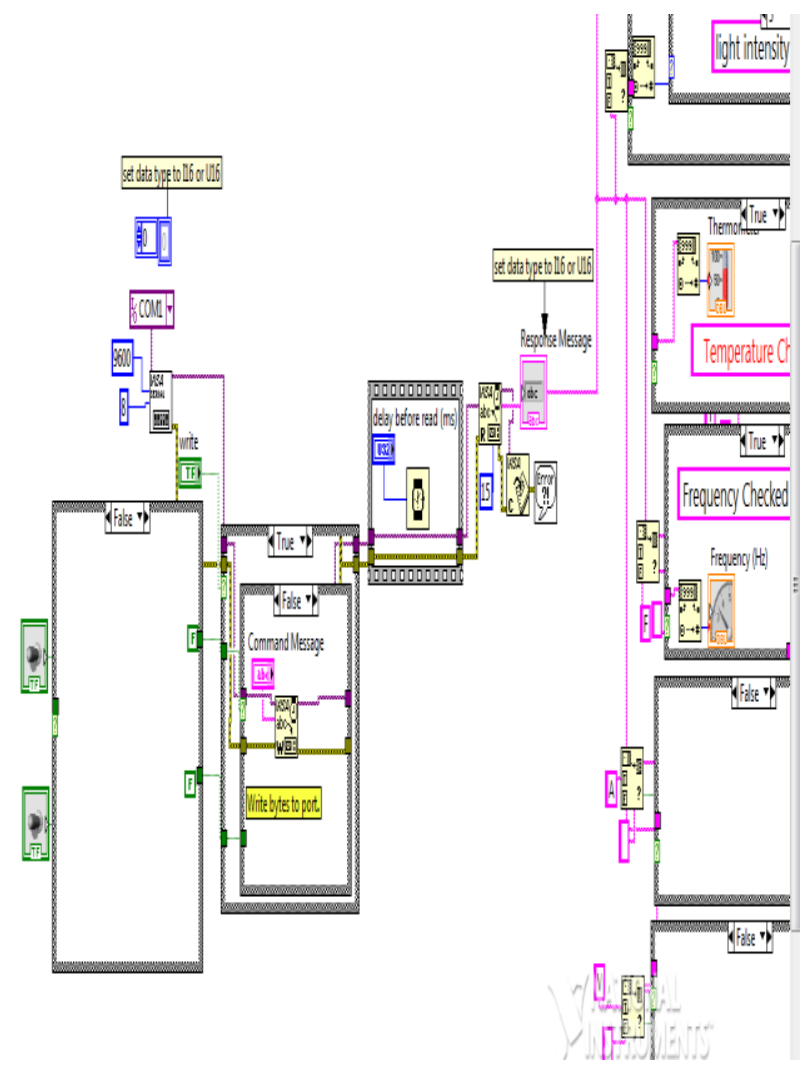

Figure11. Block diagram for serial communication in LabVIEW 


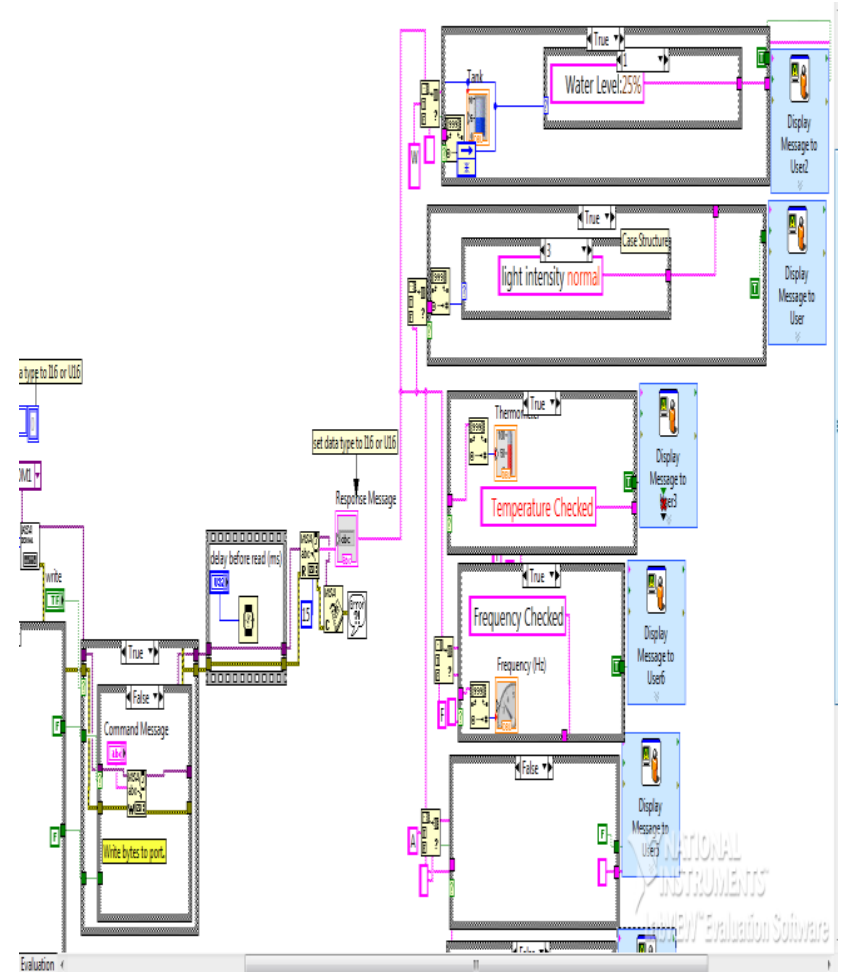

Figure 12. Block diagram for data measurement in LabVIEW

\section{Results And Discussions}

This project has been implemented, tested successfully and achieved reliable transmission of data to the remote site and representation of indications and controls with logging of data in excel sheet using LabVIEW.

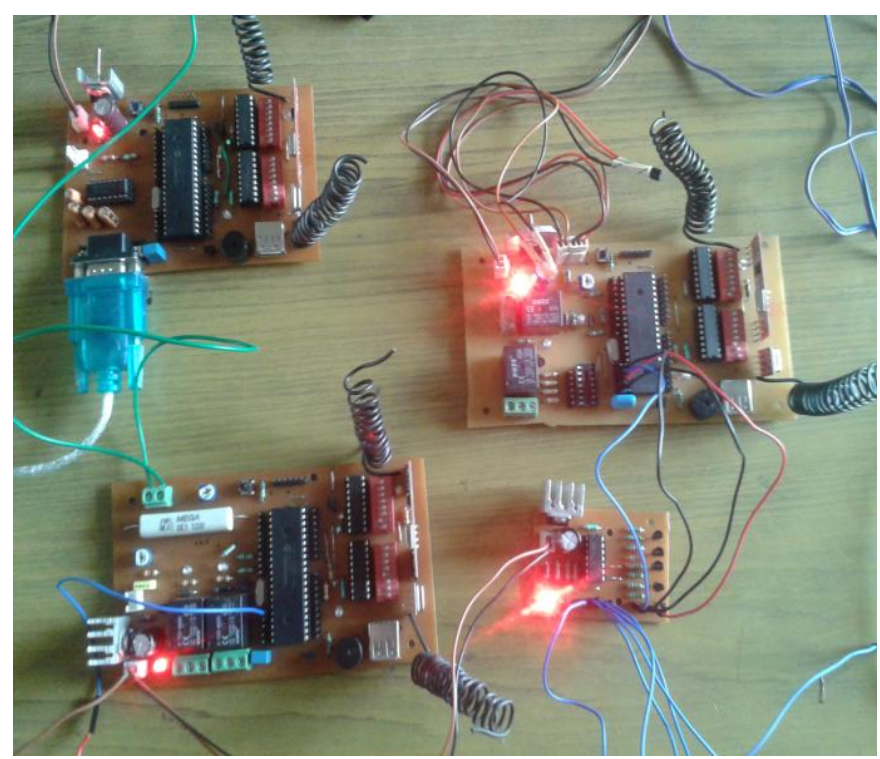

Figure13. Hardware part of industrial process management using LabVIEW 


\subsection{OUTPUT OF VARIOUS PARAMETERS IN LAbVIEW}

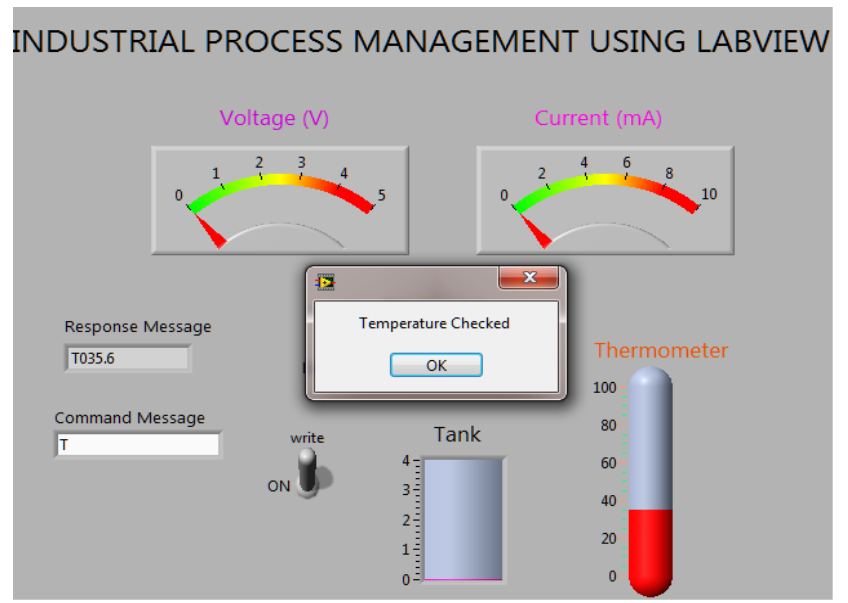

Figure 14.Output of Temperature measurement

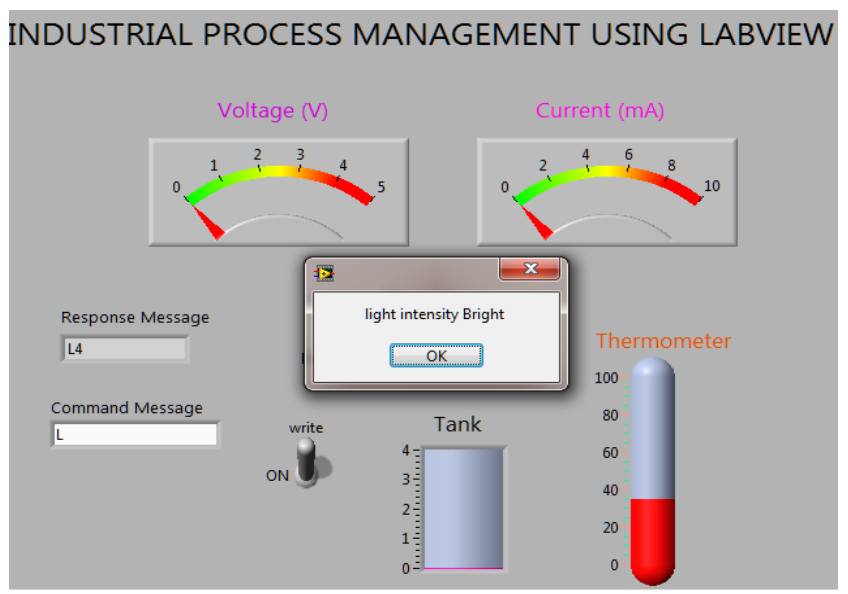

Figure 15.Output of Light intensity measurement

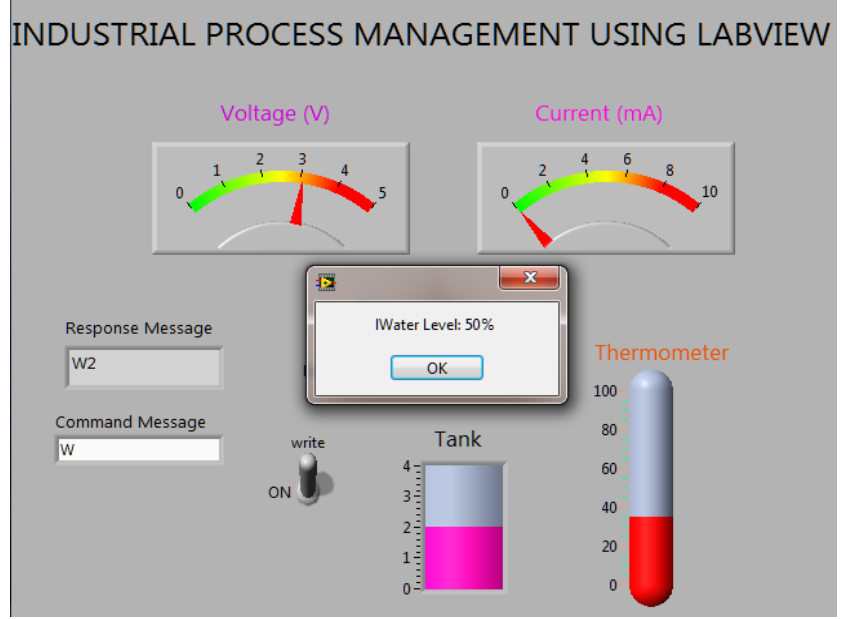

Figure 16. Output of water level measurement 


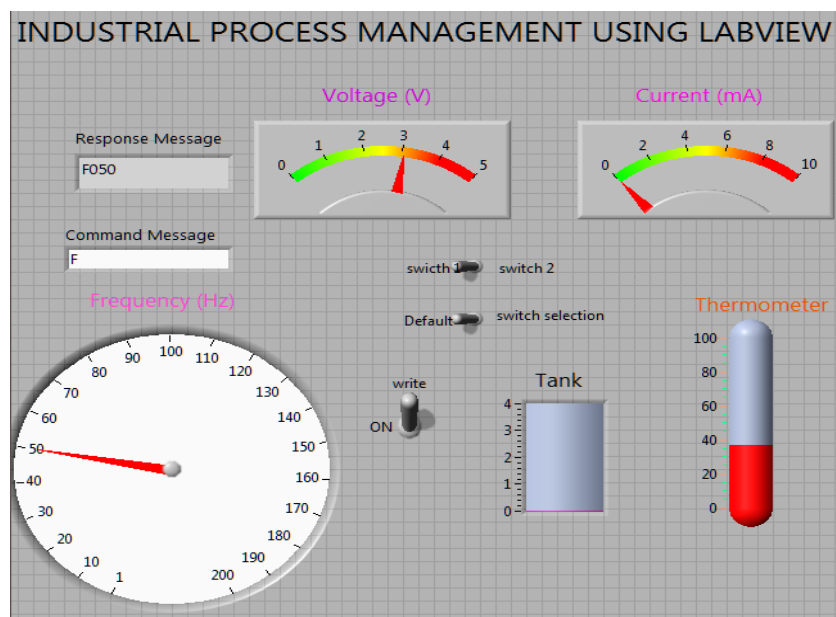

Figure 17.Output of Frequency measurement

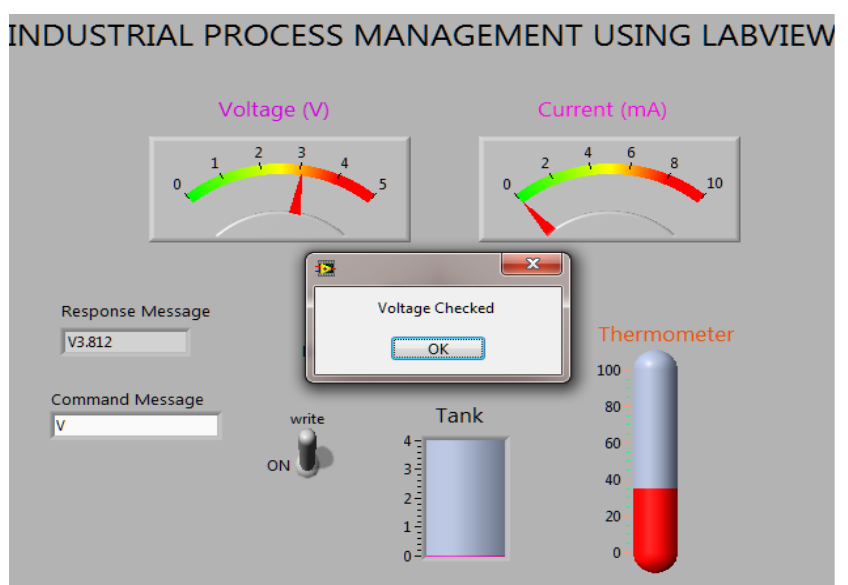

Figure 18. Output of Voltage measurement

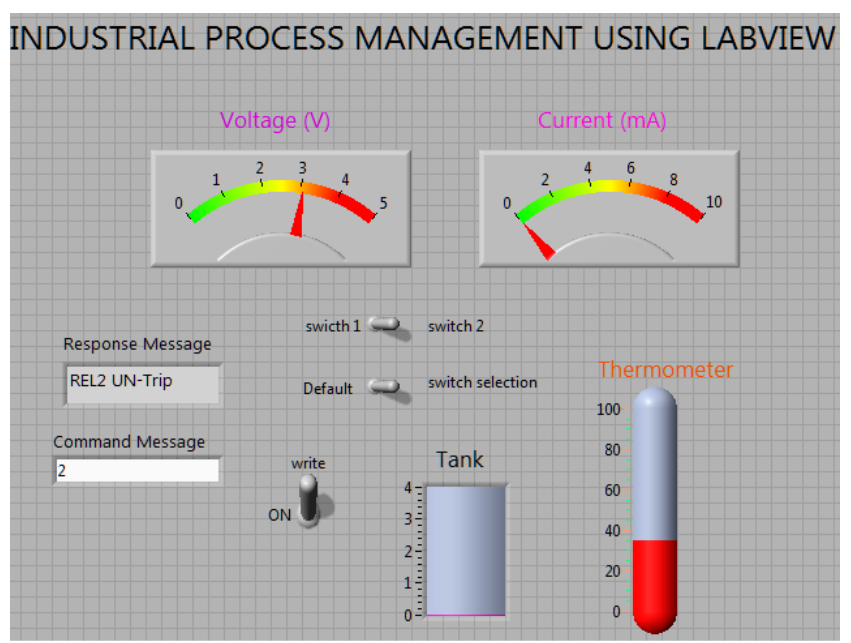

Figure 19. Output of Relay Circuit

\section{Conclusion}

In this paper, master-node architecture for real time data acquisition and logging is demonstrated and implemented. Two slaves are measuring various industrial parameters to monitor and control industrial process. Acquired data display at each slave and sent to master processor that compile the acquired information and send to remote location using RS232 serial communication and simultaneously display and log into spreadsheet the variations in quantity under measurement to local and remote system configured with LabVIEW platform. In addition, the master processes this information and generates controls signals based on predefined cases or can receive the controlling action from remote controller to control the industrial application. The paper adds the 
value simple approach for data acquisition, continuous monitoring of process parameters, less manufacturing time, ease of implementation with reliable measuring, controlling and data logging demands of industry.

\section{References}

[1] Mukesh Kumar, Sanjeev Sharma, Mansav Joshi “Design of Real Time Data Acquisition with Multi Node Embedded Systems" International Journal of Computer Applications (0975 - 8887) Volume 42- No.11, March 2012

[2] Basil Hamed "Design \& Implementation of Smart House Control Using LabVIEW" International Journal of Soft Computing and Engineering (IJSCE) ISSN: 2231-2307, Volume-1, Issue-6, January 2012

[3] LabVIEW Software 2009 by National Instruments, http://www.ni.com.

[4] Amiya Ranjan Panda, Utpal Mandal, Hare Krishna Ratha " Integrated Monitoring of Encoder Status Parameters and GUI based Remote Control Panel Using Lab view", $3^{\text {rd }}$ International Journal of Computer Applications (0975 - 8887) Volume 43No.3, April 2012.

[5] Baosheng Yang, Jianxin Li , Qian Zhang "G Language Based Design of Virtual Experiment Platform for Communication with Measurement and Control” on 2012 International Workshop on Information and Electronics Engineering (IWIEE)

[6] Wen Xinling, Zhao Cheng,"Design and Simulation of Voltage Fluctuation Rate Monitor System Based on Virtual Instrument Technology" in 2012 International Conference on Future Electrical Power and Energy Systems.

[7] Mukesh Kumar and Mansav Joshi, "Design and Implementation of Embedding Web Server for Real Time Data Acquisition and Logging System" 4th International Conference on Computer and Automation Engineering (ICCAE 2012), Mumbai, India, January 14-15, 2012

[8] LabVIEW Graphical Programming by Gary W johnsion (TMH).

[9] Zhou Hongfu; Xiao Xinyan; Tang Yong, "Serial Communication Interface Design Based on Lab VIEW and VC Mix Programming", 8th International Conference on Electronic Measurement \& Instruments, (ICEMI2007) PP44-49, (in English) (ISTP/EI, INSPEC). 